\title{
The Role of Sex and Family Variables in Burnout ${ }^{1}$
}

\author{
Christina Maslach ${ }^{2}$ \\ University of California, Berkeley \\ Susan E. Jackson \\ University of Michigan
}

Two survey studies were conducted to assess the relationship of demographic variables to the experience of job burnout. Contrary to earlier hypotheses that women are more vulnerable to this form of job stress, the results show that women do slightly better than men. However, this difference is rather small, which suggests that the sex of the employee is not a major factor in burnout. Other results show that employees who were married or who had children experienced less burnout. Job category was also an important predictor. The findings are discussed in terms of sex-role socialization, sex-typed occupations, and social support systems.

Within the last five years, there has been an explosion of interest in the phenomenon of "burnout." Generally identified as a form of job stress, burnout is a syndrome of emotional exhaustion, depersonalization, and reduced personal accomplishment that can occur among individuals who do "people-work" of some kind. Emotional exhaustion refers to a depletion of one's emotional resources and the feeling that one has nothing left to give to others at a psychological level. The depersonalization phase of burnout is the development of negative and callous attitudes about the people one works with. This depersonalized perception of others can lead staff to view their clients as somehow deserving of their troubles (Ryan, 1971; Lerner, 1980 ), and the prevalence among human service workers of this negative

\footnotetext{
'The research described in this article was supported by a Ford Foundation grant to the Center for the Study, Education and Advancement of Women, University of California, Berkeley; and by Biomedical Sciences Support Grant 3-SO5-RR-07006-08S1.

${ }^{2}$ Correspondence should be sent to Christina Maslach, Department of Psychology, University of California, Berkeley, California 94720.
} 
attitude toward clients has been well documented (Wills, 1978). A third aspect of the burnout syndrome involves a negative evaluation of one's personal accomplishments in working with people. Staff members feel unhappy about themselves and dissatisfied with their achievements on the job. The seriousness of burnout as a social problem lies in its possible links to turnover, absenteeism, poor job performance, and various types of personal dysfunction.

Although many books, articles, and pamphlets have been written about burnout, only a small minority of these are based on any sort of empirical research (see Maslach, 1982, for an annotated review). Nevertheless, many conclusions are being drawn and are being acted upon as to what causes burnout and what can be done about it. Some of these conclusions deal with the nature of job settings, while others concern the nature of the people who populate them.

One personal factor that has been the object of increasing attention is sex. Several writers have asserted that women are more at risk for burnout than men (Levine, 1981; Pines, Aronson, \& Kafry, 1981; Ryerson \& Marks, 1981). Several arguments have been marshaled in support of this conclusion. One is that as a consequence of sex-role socialization, women are more likely to get emotionally involved with the problems of their clients or patients and thus to overextend themselves emotionally. A second argument has been that women are more likely to enter "people-work" occupations (such as nursing, teaching, and counseling) and are thus more at risk for burnout. Furthermore, they are more likely to be in positions involving direct contact with people (such as "front-line" staff) and less likely to be in higher level administrative positions. A third argument has been that women are more likely than men to be responsible for the emotional needs of their family and thus are faced with a double dose of the strain of caring for others (both at home and on the job).

Although these ideas are interesting, they have not received much of an empirical test. Indeed, there has been a noticeable lack of research on the general topic of sex differences in job stress (Haw, 1982). Thus, the current research goal was to determine if there are any significant sex differences with respect to burnout and, if so, what might account for them. Two different studies were conducted. The first one was a reanalysis of the data that were used in the development of the Maslach Burnout Inventory (MBI; Maslach \& Jackson, 1981a), which looked for basic sex differences that might occur across a wide range of human service occupations. The second study utilized a nationwide survey of a single occupational group (public contact employees of a federal service agency) to look for sex differences within this one job setting. 


\section{MBI STUDY}

A critical necessity for any research on burnout is a standardized instrument for measuring it. The Maslach Burnout Inventory was developed to meet this need and is now the most widely-used research instrument in the field. The MBI has three subscales that assess the different aspects of experienced burnout: emotional exhaustion, depersonalization, and reduced personal accomplishment. It assesses both the frequency and the intensity of these feelings, and has been found to be reliable, valid, and easy to administer. The reliability coefficients for the frequency and intensity dimensions of each subscale are as follows: Emotional Exhaustion (.90 and .87), Depersonalization (.79 and .76), and Personal Accomplishment (.71 and .73). Validity was established by correlating MBI scores with (a) behavioral ratings made independently by outside observers (spouses and co-workers), (b) the presence of certain job characteristics (e.g., caseload, feedback) expected to contribute to experienced burnout, and (c) measures of various outcomes (e.g., intention to quit, job satisfaction) hypothesized to be related to burnout (see Maslach and Jackson, 1981a, $1981 \mathrm{~b}$, for more detailed psychometric analyses of the MBI).

The development of the MBI was based on a sample of 1,025 people from a wide range of health and service occupations, including police officers, nurses, teachers, agency administrators, counselors, social workers, probation officers, mental health workers, physicians, psychologists, psychiatrists, and attorneys. This sample was characterized by a relatively equal proportion of females $(54 \%)$ and males $(46 \%)$. Sixty percent of the respondents were married, while $40 \%$ were either single, divorced, or widowed. The respondents varied in age from 18 years to 70 years, with the majority in the 25-40 year range. The sample was predominantly Caucasian (89\%) and was a highly educated group (67\% had completed college and $50 \%$ had done postgraduate work).

An analysis of the data from this sample revealed sex differences for each of the MBI subscales (see Table I). However, the pattern was not a consistent one. Women showed greater burnout on two aspects (higher emotional exhaustion and lower personal accomplishment), while men showed greater burnout on one (higher depersonalization). In other words, women were more likely to feel emotionally drained and overextended by their work with people, and less likely to feel that they had accomplished a lot in that work. Men, on the other hand, were more likely to have a negative and callous view of people.

At first glance, these findings seem to support the hypothesis that sex-role socialization causes different patterns of burnout. Women are 


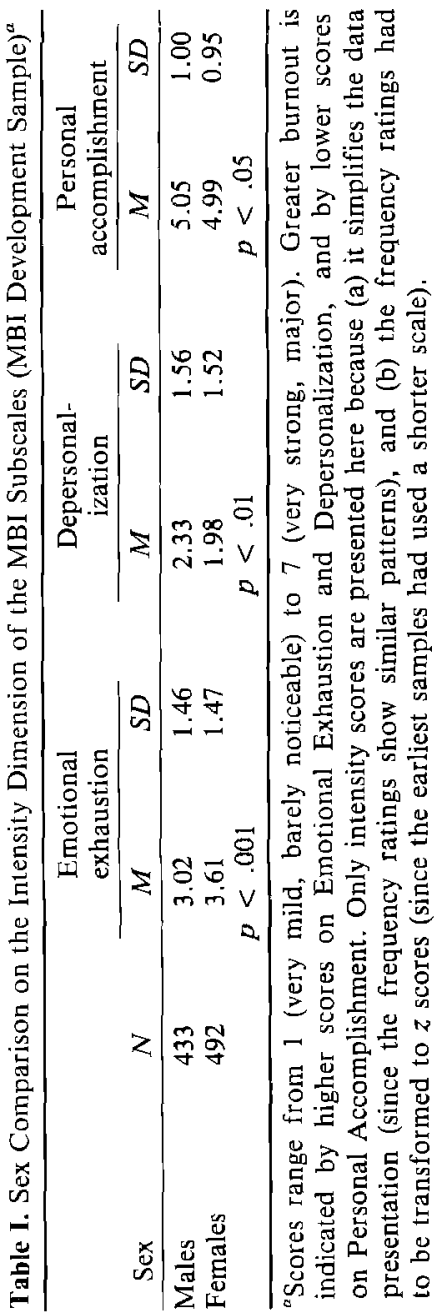


encouraged to be more emotional, empathic, and sensitive to other people's feelings, while men are encouraged to be nonemotional, independent problem solvers. Consequently, women should be at greater risk for emotional overinvolvement, while men should be more prone to deal with people in depersonalized ways.

However, one must be cautious about accepting this sex-role explanation. First, the sex differences are very small ones in an absolute sense (less than 1 point on a 7-point scale). Their statistical significance derives largely from the large sample size, since they account for very little of the variance. It would be an error to interpret these minor differences in major terms, since the differences are far less than the sex similarities.

A second reason for caution is that sex is clearly confounded with type of occupation. Many of these human service professions are sex segregated, with one sex being far more predominant than the other. In the MBI development sample, the physicians, police officers, and psychiatrists were usually men, while the nurses, social workers, and counselors were usually women. Therefore, the sex differences may actually reflect differences in occupations (as argued by the second hypothesis). However, it is impossible to determine whether occupational roles or sex roles are more critical because sex and occupation cannot be disentangled from each other. For example, in our study of health care professionals (Maslach \& Jackson, 1982), we found that nurses scored much lower on depersonalization than physicians. Does this finding tell something about the different working relationships that nurses and physicians have with patients? Or does it reflect a sex-role difference in sensitivity and empathy, since almost all of the nurses were women and most of the physicians were men?

The confounding of sex and occupation can be avoided by looking at sex comparisons within a single occupation. If the sex differences then disappear, it is likely that they were actually due to occupational characteristics. However, if sex differences still emerge when occupation is held constant, then there is greater support for the effect of sex-role socialization. The next study provided an excellent opportunity for this sort of within-occupation analysis.

\section{AGENCY STUDY}

This study involved a nationwide survey of public contact employees in a federal service agency. These employees consist of claim representatives, service representatives, and telephone service representatives. They are all involved in personal service to the public, although their specific tasks differ. Claims representatives (CRs) are responsible for authoriz- 
ing benefits, adjudicating claims, and determining if claims are valid. Service representatives (SRs) give preliminary information to clients and assist the CRs by compiling and organizing the clients' cases. The telephone service representatives (TSRs) answer inquiries over the telephone and thus have no face-to-face contact with the clients.

The original purpose of the study was to determine the extent to which public contact employees were experiencing burnout and to identify possible precursors or sources of such stress. Because the sample was both a large and representative one, it was also well suited for our analysis of sex differences. Only the data relevant to this analysis are presented here; other findings are described in Maslach and Jackson (1984).

\section{METHOD}

From within each of the three occupational categories (CRs, SRs, TSRs), employees were selected on a random basis to establish a reliable, reasonably bias-free representation. Each of the three occupational subsamples was stratified by geographic region and by grade level to further ensure that the characteristics of the participants would accurately reflect those of all their counterparts in agency field offices. Confidential survey forms were mailed to a $5.5 \%$ sample $(n=1,009)$ of these public contact employees. The surveys were completed anonymously and returned directly to us (rather than through traditional management channels). Completed surveys were received from 845 of these people, which constitutes a response rate of $84 \%$.

The survey consisted of three sections. The first section asked for demographic information (sex, age, race, marital status, children, educational level); occupational information (job, grade, region, specialty work area, length of time in present job, length of time in public contact work, hours per week in public contact); and information about the clientele (age, sex, race, socioeconomic status, number served per day, type of contact). The second section consisted of the MBI, which yielded two scores (frequency and intensity) for each of the three subscales (Emotional Exhaustion, Depersonalization, Personal Accomplishment). The third section asked the employee to rate his or her evaluation of the job. One rating dealt with job preparation ("I have or will receive sufficient job training") and another with co-workers relations ("I feel free to discuss job problems with my co-workers at work"). Another four ratings were combined into a single index of office environment because they were all intercorrelated $(r \geqslant .30)$, and they all loaded on a single factor in a factor 
analysis (factor loadings of .60 or greater). These ratings included "The work is well-organized in my office," "I have enough say in how I do my work," "I receive adequate performance feedback from my supervisor," and "I can go to my supervisor for help with personal problems." The final ratings dealt with job dissatisfaction, as measured by intention to quit ("I don't plan to be working in this office 12 months from now") and desire for less public contact ("I would like to spend less time dealing with the public").

\section{Results}

Demographic Factors. The employees who participated in the survey were predominantly female ( $71 \%$ ). Although women were in the majority in each of the three job categories, their plurality was greatest within the SR position $(85 \%)$ and least within the CR position $(58 \%)$. Stated from another perspective, $56 \%$ of the men surveyed were CRs (compared to $31 \%$ of the women), and only $20 \%$ of the men were SRs (compared to $46 \%$ of the women). There was no such sex difference within the TSR group.

The sample was a fairly young group, with $43 \%$ of the employees being less than 30 years old. Slightly more than 3 out of every 4 respondents were White, $15 \%$ were Black, $5 \%$ were Hispanic, and all other ethnic groups were less than $2 \%$. A greater proportion of the Nonwhite sample was female $(79 \%)$ than was the White sample $(68 \%)$.

About $58 \%$ of the employees indicated that they were married, and $41 \%$ were responsible for supporting at least one child or dependent adult. There were no sex differences on either of the variables-men were just as likely as women to be married and to have family responsibilities. However, there was a difference by job category. SRs were the most likely to be married, and a greater percentage of them had dependents than did the respondents in the other categories.

In terms of educational level, about $46 \%$ of the participants held a minimum of a bachelor's degree from college. There was a striking sex difference here- $69 \%$ of the men were college graduates; compared to $36 \%$ of the women. Also, more CRs had a college degree $(71 \%)$ than either TSRs $(39 \%)$ or SRs $(25 \%)$.

Forty-four percent of the employees had been working in their present position, grade, and office for less than a year. On the other hand (when taking into account both their government and nongovernment service), fully two-thirds of the sample reported that they had had more than 5 years of overall experience in working with the public. Proportionately more 
women $(72 \%)$ had had over 5 years of such experience than the men $(57 \%)$. By job category, more SRs $(76 \%)$ had had over 5 years experience in working with the public than either CRs or TSRs $(62 \%)$.

When asked to specify the approximate number of clients they serve on a typical workday, the most frequent response given by the total sample was " 40 or more" $(36 \%)$. Job category was an extremely important factor in daily caseload. Nearly all of the TSRs $(98 \%)$ said that they serve an average of 40 or more clients per day, as compared to only $32 \%$ of the SRs who said they did so. Conversely, hardly any of the CRs $(2 \%)$ had a caseload of this magnitude, with the majority $(87 \%)$ serving 19 clients or less on a typical workday.

Sex was also a factor here, with men having a smaller caseload than women. Fifty-two percent of the men had a caseload of 19 clients or less per day, compared to $37 \%$ of the women.

Burnout Scores. The pattern of burnout among male and female public contact employees was both similar to, and different from, the findings of the MBI study (see Table II). The most striking similarity was that men continued to score significantly higher than women on both dimensions of depersonalization. However, there was less evidence of sex differences on the other two subscales. There were no sex differences in the frequency of either emotional exhaustion or personal accomplishment, but women scored higher on both intensity dimensions. The latter finding replicates the MBI study for the Emotional Exhaustion subscale, but it is in the reverse direction for personal accomplishment. The same caution holds here as in the MBI study: The absolute differences between the sexes are very small and should not be overinterpreted.

The variables of marital status and children were also investigated, since one of the sex difference hypotheses had argued for the importance of family responsibilities. Although there was a consistent pattern of lower burnout scores for married employees than for nonmarried (single, divorced, widowed), the differences were very small and often of marginal statistical significance. The pattern was far more striking with respect to the presence or absence of children in the family. Compared to employees who had one or more children, childless employees showed more burnout on all aspects of the syndrome. Sex did not interact significantly with either marital or family status.

An important predictor of burnout scores proved to be job category. There was a consistent pattern across all three subscales: TSRs had the highesi burnout scores, SKs had the lowest, and CRs were in between. There were no significant interactions of sex and job category, which suggests that the result cannot be explained by the confounding of these two variables. Rather, the relationship of sex to burnout seems to be independent of the type of contact that the employees had with the public. 


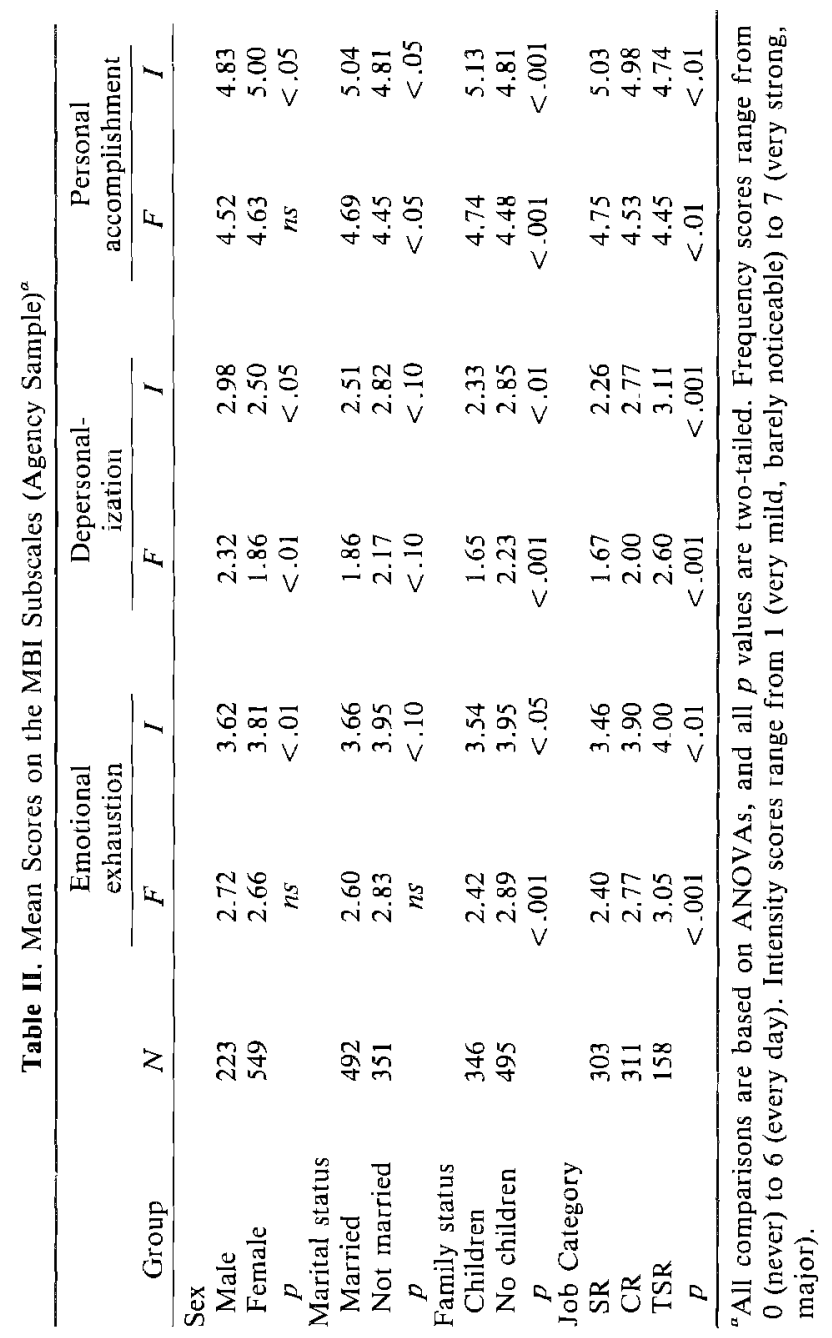


Table III. Contribution of the Sex Variable to Multiple Regression Analyses of Burnout ${ }^{a}$

\begin{tabular}{|c|c|c|c|c|c|c|}
\hline \multirow[b]{2}{*}{ Step and variables entered } & \multicolumn{3}{|c|}{ Frequency } & \multicolumn{3}{|c|}{ Intensity } \\
\hline & $R$ & $R^{2}$ & Increase $\overline{R^{2}}$ & $R$ & $R^{2}$ & Increase $R^{2}$ \\
\hline \multicolumn{7}{|l|}{ Depersonalization } \\
\hline 1. Job, marital, family & .328 & .1076 & & .304 & .0926 & \\
\hline 2. Sex & .342 & .1170 & $.0094^{c}$ & .315 & .0990 & $.0064^{b}$ \\
\hline \multicolumn{7}{|l|}{ Emotional Exhaustion } \\
\hline 1. Job, marital, family & .275 & .0756 & & .244 & 0597 & \\
\hline 2. Sex & .276 & .0762 & .0006 & .263 & .0692 & $.0095^{c}$ \\
\hline \multicolumn{7}{|l|}{ Personal Accomplishment } \\
\hline 1. Job, marital, family & .222 & .0495 & & .196 & .0386 & \\
\hline 2. Sex & .236 & .0556 & $.0061^{b}$ & .210 & .0440 & $.0054^{b}$ \\
\hline
\end{tabular}

${ }^{a}$ All $F$ tests of increments in $R^{2}$ are based on 1 and 839 degrees of freedom.

${ }^{\mathrm{b}} p<.05$.

${ }^{c} p<.01$.

A better test of the sex difference hypothesis would be to see if sex accounts for additional variance in burnout, beyond what is predicted by job category, marital, and family status. Multiple regression analyses were performed for each of the MBI scales, in which job category, marital status, and family status were entered on the first step and sex on the second (Kerlinger \& Pedhazur, 1973). As can be seen in Table III, sex added a statistically significant increment to all of the regression equations, with the exception of frequency of emotional exhaustion. It should also be apparent from Table III that the magnitude of these increments is exceedingly small. Although statistically significant (undoubtedly because of the large sample size), the relationship of sex to burnout is clearly of minor, or even trivial, importance.

Job Ratings. For the public contact employees, burnout was linked to their evaluation of their work. Higher burnout scores on all of the MBI subscales correlated significantly $(p<.001)$ with a poorer index of office environment (correlations ranged from .30 to .43 ), poorer co-worker relations (.11 to .21$)$, and poorer job preparation (.11 to .24). Relationships were also found between burnout and job satisfaction. Higher burnout scores on all of the MBI subscales correlated significantly with the desire to spend less time with the public (correlations ranged from .31 to .53) and the intention to quit the job (.18 to .33 ).

For the three job evaluation ratings, there were no significant main effects or interactions of the sex, marital status, and family status variables. Only job category was an important factor. Consistent with the earlier findings, SRs had the most positive evaluations, TSRs had the most negative, and CRs were in between, for co-worker relations, $F(2,835)=$ 
Table IV. Mean Scores for Job Dissatisfaction Measures ${ }^{a}$

\begin{tabular}{lccc}
\hline \multicolumn{1}{c}{ Group } & $N$ & $\begin{array}{c}\text { Intention } \\
\text { to quit job }\end{array}$ & $\begin{array}{c}\text { Desire for less } \\
\text { public contact }\end{array}$ \\
\hline Sex & & & \\
Male & 244 & 3.02 & 3.07 \\
Female & 593 & $\begin{array}{r}3.39 \\
\quad\end{array}$ & 3.30 \\
$p$ & & $<.001$ & $<.05$ \\
Marital status & & & \\
Married & 487 & 3.44 & 3.37 \\
Not married & 350 & 3.07 & 3.03 \\
$p$ & & $<.01$ & $<.05$ \\
Family status & & & \\
Children & 346 & 3.45 & 3.48 \\
No children & 491 & 3.16 & 3.05 \\
$p$ & & $<.10$ & $<.01$ \\
Job category & & & \\
SR & 320 & 3.43 & 3.53 \\
CR & 321 & 3.37 & 3.15 \\
TSR & 196 & 2.90 & 2.89 \\
$p$ & & $<.001$ & $<.001$ \\
\hline
\end{tabular}

${ }^{a}$ All comparisons are based on ANOVAs, and $p$ values are twotailed. Scores on both measures range from 1 (strongly agree), indicating high dissatisfaction, to 5 (strongly disagree), indicating low dissatisfaction.

$10.46, p<.001$, and for office environment, $F(2,835)=2.52, p<.10$. The one exception to this pattern was that $C R s$ had the most negative evaluation of their job training, $F(2,835)=7.53, p<.001$.

However, for the two measures of job dissatisfaction, there were significant main effects (but not interactions) of sex, marital status, family status, and job category (see Table IV). Men were more dissatisfied than women, in that they expressed a stronger intention to leave their job and to spend less time working with the public. Similarly, greater dissatisfaction was shown by employees who were not married and by those who were childless. Job category showed the same pattern as before: TSRs were the most dissatisfied, SRs were the least, and CRs were in between.

\section{DISCUSSION}

Taken together, the results of the MBI and agency studies suggest that (a) sex is not a major factor in burnout; (b) when a sex difference does exist, it is in the reverse direction of what is usually predicted. The first conclusion is based on the findings that the differences between men and women are 
quite small (or nonexistent) and account for only a very small part of the variance. Thus, any further pronouncements on which sex experiences more burnout would not seem to be very productive for our understanding of the burnout phenomenon. Being male or female, in and of itself, is not a critical determinant of burnout (although, as we shall argue later, certain correlates of sex may be significant).

The only consistent sex difference to emerge from the data analyses appears on the depersonalization aspect of burnout. Men continue to score higher than women, both across occupations and within the agency sample. This same sex difference in depersonalization has been found in a sample of 469 teachers by Schwab and Iwanicki (1982). All of this evidence suggests that the sex difference in depersonalization may be a reliable one, and not simply the result of the different work that men and women do. However, this difference is contrary to popular belief-women are doing better than men in terms of burnout, rather than doing worse. Within the agency sample, this finding is particularly striking, since the women had even more public contact work than the men (as measured by number of hours per week in direct public contact, number of clients served, and number of years in this type of work). These results suggest that women may have an edge over men in dealing with the emotional strains of "people-work"-an interpretation that is supported by the findings that women were less desirous of cutting down their contact with the public and were less inclined to quit the job.

What might account for this small but consistent sex difference? Three types of explanations were described earlier-sex-role socialization, sex-typed occupations, and family responsibilities-and although they were proposed to explain the opposite effect, they are relevant to the actual results. Because the depersonalization difference was found within occupations, it cannot be explained by sex biases in the jobs held by men and women. A more likely explanation involves sex-role socialization. The female role emphasizes caring, nurturance, and concern for other people and their well-being; consequently, women would be less likely to respond to people and their problems in an impersonal and callous manner. The slight elevation in intensity of emotional exhaustion for women could also be interpreted in terms of the female role and its emphasis on emotionality. In addition, the greater intensity of job dissatisfaction expressed by men could be linked to their expectations for success, as determined by the emphasis in the male role on competition, achievement, and work identity.

Although sex-typing in occupations did not account for the depersonalization difference, there was still some confounding of job and sex within the agency sample. Men were more likely to be CRs-a position with more pay, prestige, and decision-making authority. Women were more 
highly represented within the SR position, which involves more contact with clients, but not the final responsibility for adjudication of their claims. Thus, it is possible that the sex difference in depersonalization could be partially determined by these differences in the relationship with clients. However, the results revealed a small but independent effect of sex over and above job category. Furthermore, the most consistently burned out group (across all aspects of burnout, not just one) was the TSRs, who did not have a biased sex distribution.

Another variable that was confounded with both sex and job category was amount of education. Men were more highly educated than women and were thus more likely to have (a) entered their job directly from college and (b) qualified for the higher level CR position. On the other hand, many of the women did not have a college education and had started in the agency as clerical workers. They were then promoted internally from the clerical ranks to positions as SRs. Clearly, differences in education led to different career tracks, which in turn were linked to differential burnout rates.

Education may have also had some important psychological implications for burnout. It is possible that people with higher levels of education have greater expectations for their future career and for what they will accomplish in life. A college degree may be viewed as a guaranteed ticket to jobs with greater pay, prestige, and power. If the job they actually get fails to meet these expectations, then these persons may be unhappy and dissatisfied with it. However, the same job may be a source of pride and satisfaction to someone who did not have so much formal schooling, and consequently, did not have such high career expectations. This difference in expectations, as a function of education, may be one important reason why female employees (who were less well educated) were more satisfied with their job. Indeed, the greatest job satisfaction and the lowest burnout rate were displayed by the SRs, most of whom were women with little or no college education. Given that they had started out in clerical jobs and had worked themselves up to SR positions, they may have had a more developed sense of accomplishment, higher professional self-esteem, and greater identification with the goals and values of the agency.

There was no evidence to support the argument that increased family responsibilities would be correlated with greater burnout and that this would be more true for women than for men. Rather, the results showed the opposite effect-employees with children scored lower on all three aspects of burnout than did employees who were childless, and this was equally true for both sexes. One interpretation of these findings is that people who are parents are likely to be older and at a later, more mature phase of their psychological development. Having settled down and started a family, they may have a nore stable life-style and a different perspective on life. 
Another, related, explanation is that people who have families to support have a different outlook on their jobs. Salary, benefits, and long-term security will be more important factors to them than excitement and personal fulfillment. In contrast, personal fulfillment and satisfaction may be valued more highly by childless individuals, since they do not have to worry about anyone other than themselves (in most cases) and may feel freer to change jobs if their current one is less than ideal. Furthermore, childless employees may be more likely to use their job as a source of their social life, and this could lead them to get overly involved with people at work and become more at risk for burnout.

A third explanation for the relationship between family variables and burnout is that family life may make people more experienced in dealing with other individuals and their problems. When people become parents, they receive a great deal of on-the-job practical training in problem solving, conflict resolution, interpersonal communication, and reduction of emotional distress. Consequently, they may not only be more experienced in working with people but also may have developed greater patience and a more balanced perspective in responding to crises. Finally, another interpretation of these findings is that a family is actually an emotional resource, rather than an emotional drain. The love, aid, and comfort provided by family members can help the individual cope more effectively with job stress, as suggested by research on social support systems (Caplan \& Killilea, 1976; Cobb, 1976; House, 1981). The psychological rewards of having children may thus outweigh the costs in time, effort, and money which are so often cited as the parental burden.

Because all of these explanations are post hoc, no data had been collected to assess their validity. Greater understanding of the relationship between family life and burnout will require research studies designed specifically to investigate this intersection of home and work, rather than relying on the sort of post hoc data analyses presented here. The current studies do not actually demonstrate the causal direction of the relationships, although our assumption has been that demographic variables influence burnout, since they are antecedent in time. However, in the case of certain family variables, it is likely that a reciprocal causality exists between family life and burnout. Here we have speculated on how the experience of parenthood may alter one's susceptibility to burnout; elsewhere we have discussed how burnout on the job can alter one's behaviors at home and thus affect the quality of family life (Jackson \& Maslach, 1982). Undoubtedly, the interrelationships between work and home are very complex and difficult to untangle, and this may be one reason why they have been so little studied in the past. Their importance is underscored by findings such as those in the agency survey, and our hope is that this will 
inspire future researchers to investigate more thoroughly this intersection of household and marketplace.

\section{REFERENCES}

Caplan, G., \& Killilea, M. (Ed.). Support systems and mutual help. New York: Grune \& Stratton, 1976.

Cobb, S. Social support as a moderator of life stress. Psychosomatic Medicine, 1976, 38, 300-314.

Haw, M. A. Women, work and stress: A review and agenda for the future. Journal of Health and Social Behavior, 1982, 23, 132-144.

House, J. S. Work stress and social support. Reading, Mass.: Addison-Wesley, 1981.

Jackson, S. E., \& Maslach, C. After-effects of job-related stress: Families as victims. Journal of Occupational Behaviour, 1982, 3, 63-77.

Kerlinger, F., \& Pedhazur, E. Multiple regression in behavioral research. New York: Holt, 1973.

Lerner, M. J. The belief in a just world: A fundamental delusion. New York: Plenum, 1980.

Levine, G. I quit!: A guide to burnout prevention. Orange, Calif.: Indeco, 1981

Maslach, C. Burnout: The cost of caring. Englewood Cliffs, N.J.: Prentice-Hall, 1982.

Maslach, C., \& Jackson, S. E. The Maslach Burnout Inventory. Research edition. Palo Alto: Consulting Psychologists Press, 1981. (a)

Maslach, C., \& Jackson, S. E. The measurement of experienced burnout. Journal of Occupational Behaviour, 1981, 2, 99-113. (b)

Maslach, C., \& Jackson, S. E. Burnout in health professions: A social psychological analysis. In G. Sanders \& J. Suls (Eds.), Social psychology of health and illness. Hillsdale, N.J.: Erlbaum, 1982. Pp. 227-251.

Maslach, C., \& Jackson, S. E. Patterns of burnout among a national sample of public contact workers. Journal of Health and Human Resources Administration, 1984, 7, 189-212.

Pines, A. M., Aronson, E., \& Kafry, D. Burnout: From tedium to personal growth. New York: Free Press, 1981.

Ryan, W. Blaming the victim. New York: Pantheon, 1971.

Ryerson, D., \& Marks, N. Career burnout in the human services: Strategies for intervention. In J. W. Jones (Ed.), The burnout syndrome. Park Ridge, Ill.: London House Press, 1981. Pp. 151-164.

Schwab, R. L., \& Iwanicki, E. F. Who are our burned out teachers? Educational Research Quarterly, 1982, 7(2), 5-16.

Wills, T. A. Perceptions of clients by professional helpers. Psychological Bulletin, 1978, 85, 968-1000. 